DOI 10.37882/2223-2982.2021.09-2.16

\title{
ФОРМИРОВАНИЕ ПРОФЕССИОНАЛЬНОЙ ИНОЯЗЬЧНОЙ КОМПЕТЕНЦИИ С ПОМОЩЬЮ ВЫЯВЛЕНИЯ НАЦИОНАЛЬНОГО КУЛЬТУРНОГО КОДА ПУТЕШЕСТВИЯ ПО ЖЕЛЕЗНОЙ ДОРОГЕ
}

\section{PROFESSIONAL FOREIGN LANGUAGE COMPETENCE FORMATION BY ELICITING THE NATIONAL CULTURE CODE OF RAILWAY TRAVEL}

E. Liakhova

E. Fedotkina

Summary: The article is devoted to the problem of increasing the efficiency of teaching a professionally oriented foreign language in a nonlinguistic university. The authors of the article propose to use the method of identifying the national culture code as a tool for the formation of professional foreign language competence in the process of teaching a foreign language (English) to future PR specialists of railway transport. One of the paramount skills for a public relations specialist is the ability to identify the hidden motives of the consumer or the so-called culture code of goods and services, which is especially important for promoting domestic goods and services on the world market. The authors put forward a hypothesis that the study of the Russian and English culture codes of travel by rail will enhance the effectiveness of teaching English of the specialty and the success of the professional-cultural competence formation as a component of the foreign language professional competence of future PR specialists.

Keywords: non-linguistic university, professional-cultural competence formation, increasing the effectiveness of teaching a foreign language, the Russian culture code of railway travel.

\author{
Ляхова Елена Георгиевна \\ К.n.н., дочент, Российский университет транспорта \\ (МИИТ) (Москва); Московский государственный \\ лингвистический университет \\ liakhoval@mail.ru \\ Федоткина Елена Викторовна \\ К.п.н., доцент, Российский университет транспорта \\ (МИИТ) (Москва) \\ fedotkina@mail.ru
}

Аннотация: Статья посвящена проблеме повышения эффективности обучения профессионально ориентированному иностранному языку в неязыковом вузе. Авторы статьи предлагают использовать метод выявления национального культурного кода как инструмент формирования профессиональной иноязычной компетенции в процессе обучения иностранному языку (английскому) будущих PR специалистов железнодорожного транспорта. Одним из первостепенных умений для специалиста в сфере связей с общественностью является умение выявлять скрытые мотивы потребителя или так называемый культурный код товаров и услуг, что особенно важно для продвижения отечественных товаров и услуг на мировом рынке. Авторы выдвинули гипотезу о том, что изучение российского и английского культурных кодов путешествия по железной дороге будет способствовать повышению эффективности обучения английскому языку специальности и успешности формирования профессионально-культурной компетенции как составляющей иноязычной профессиональной компетенции будущих PR специалистов.

Ключевые слова: неязыковой вуз, формирование профессионально-культурной компетенции, повышение эффективности обучения иностранному языку, российский культурный код путешествия по железной дороге.

\section{Введение}

$\mathrm{B}$ результате овладения курсом по иностранному языку делового общения у студентов должна быть сформирована межкультурная иноязычная коммуникативная профессионально ориентированная компетенция, которая представляет собой комплекс субкомпетенций, формируемых в результате выполнения выделяемых преподавателем конкретных задач этого учебного курса [2]. Субкомпетенции, составляющие курс, интерпретируются согласно целям обучения, и среди них можно выделить лингвистическую, социокультурную, социолингвистическую, прагматическую, социальную, стратегическую, дискурсивную и компенсаторную субкомпетенции [2]. Названные компетенции являются самостоятельными частными целями, которые достигаются при выполнении комплекса заданий. В за- висимости от конкретной профессии обучаемых характер и количество заданий варьируется. В том числе и сами субкомпетенции могут приобретать более или менее приоритетное значение, исходя от сферы общения и от преобладающего вида речевой деятельности будущих специалистов [2]. В частности, при преподавании иностранного языка будущей профессии студентам неязыковых вузов необходимо уделять внимание формированию профессионально-культурной компетенции, включающей в себя знания, умения и навыки выявления и использования национального культурного кода товаров и услуг в профессиональной деятельности $[1,5]$. Исследователи полагают, что подобный подход к обучению иностранных языков в неязыковых вузах существенно повышает результативность обучения.

Проанализировав различные исследования наи- 
более востребованных профессиональных навыков PR менеджера в сфере транспорта $[4,6,9]$, можно прийти к выводу, что самым главным качеством, необходимым для PR специалиста, многие ученые называют умение и навыки грамотной работы с клиентами. Желания клиентов, как правило, изучаются PR специалистами, используя универсальный метод изучения потребительского спроса в виде анкетного опроса, который представляет собой специальные анкеты с вопросами про исследуемый товар или товарную группу, на которые отвечают покупатели [9]. Но, некоторые исследователи считают, что посетители не всегда отвечают то, что на самом деле думают. Они отвечают первое, что им приходит в голову, так как опрос проходит в быстром темпе. А их истинные мнения о товаре так и остаются невысказанными [7]. Не менее популярным методом исследования того, что хотят клиенты, являются исследования, основанные на изучении СМИ. Проанализировав отзывы клиентов в соц. сетях, можно понять их восприятие и ожидания предлагаемых услуг [9]. Причем все больше и больше внимания исследователи потребительского рынка уделяют скрытым подсознательным желаниям людей, стараясь заранее угадать потребности и капризы потребителей. В этой связи специалисты по связям с общественностью стали включать в свои отчеты фактор культуры или культурный код $[7,8]$.

Культурный код - это подсознательный смысл, который приобретают предметы, отношения, даже страны для людей определённой культуры. Живя в своей стране, говоря на родном языке, люди с детства получают опыт, проходя через этапы взросления. Этот опыт пропитан особенностями той культуры, в которой они выросли. Отсюда Клотер Рапай делает вывод о том, что в рамках одной культуры можно выявить определенные ожидания населения о каждом социально-значимом объекте, товаре или услуге. Эти подсознательные ожидания являются не чем иным, как запросом общества. Если маркетолог сумеет правильно расшифровать этот запрос и грамотно использовать его в рекламной компании, то такая рекламная компания станет идеальной и завоюет души всех потребителей в этой стране [7].

Культурный код товаров и услуг может быть расшифрован с помощью проведения специально организованных опросов населения, во время которых людей просят расслабиться, вспомнить свой опыт, связанный с определенным товаром, и ответить на вопросы исследователя [7]. Использование этой методики при обучении иностранному языку позволяет существенно повысить результаты усвоения иностранного языка студентами неязыковых вузов за счет формирования профессионально-культурной компетенции будущих специалистов $[1,5]$.

Для транспортного предприятия выявление культур- ного кода железной дороги, или другими словами, исследование истинных запросов населения, их ожиданий от железнодорожного транспорта, может помочь грамотно выстроить всю политику этой сферы транспорта $[4,6]$. Подобное исследование раскроет подсознательные предпочтения российского потребителя и желания иностранных гостей нашей страны. Сопоставив запросы российского потребителя с запросами потребителей из других стран, можно понять, какие изменения в работе транспортной системы и рекламе обеспечат успех российского железнодорожного транспорта на международном рынке.

С точки зрения компетенций специалиста в сфере связей с общественностью в железнодорожном транспорте знания, умения и навыки исследовать и выявлять культурный код российской железной дороги для разных категорий клиентов является одной из ведущих компетенций, позволяющих правильно продумать PRконцепцию, в которой решаются вопросы позиционирования компании на рынке и разработать PR-стратегию, представляющую список проектов и программ по продвижению бренда $[4,6,9]$.

\section{Материалы, методы и результаты исследования}

Мы предлагаем использовать в качестве инструмента формирования межкультурной иноязычной коммуникативной профессионально ориентированной компетенции у будущих специалистов в сфере связей с общественностью железнодорожного транспорта России метод исследования культурного кода путешествия по железным дорогам, выдвигая в качестве гипотезы предположение о том, что подобное обучение позволит повысить эффективность формирования профессионально-культурных умений и навыков студентов в ситуации профессионального иноязычного общения.

Для исследования нашего предположения был использован метод эмпирического исследования -педагогический эксперимент, а также методы сбора эмпирических данных - тестирование и математико-статистические методы обработки полученных данных.

В процессе педагогического эксперимента мы применили эмпирические методы изучения научно-методической литературы по темам «Культурный код и поведение потребителя» «Что думают пассажиры о железнодорожном транспорте в России» «Мнение пассажиров о железнодорожном транспорте в Великобритании», наблюдение за поведением студентов во время экспериментального обучения, создание специальных учебных ситуаций, диагностирующие работы, а также более узкий специализированный метод лингводидактического тестирования диалогического и монологического видов речи. 
Замысел эксперимента состоял в том, чтобы организовать и провести обучение английскому языку в форме деловой игры, имитирующей профессиональную деятельность PR специалистов в сфере изучения потребительского спроса пассажиров железнодорожного транспорта, основанного на методике Клотера Рапайя [7], в результате которой должно было произойти формирование элементов профессионально-культурной компетенции. Так как профессионально-культурная компетенция является составляющей межкультурной коммуникативной профессионально ориентированной компетенции, то формирование подобных профессионально-культурных умений и навыков могло привести к увеличению эффективности обучения английскому языку при неизменных затратах времени. Объектом исследования стал процесс формирования умений и навыков исследования и определения национального культурного кода товаров и услуг на основе методики Клотер Рапайя [7]. Цель эксперимента составило выявление, определение и обоснование особенностей формирования элементов профессионально-культурной компетенции на занятиях по английскому языку специальности с будущими PR менеджерами в процессе расшифровки национального культурного кода железной дороги. Предварительная гипотеза эксперимента состояла в предположении о том, что формирование профессионально-культурных умений и навыков будущих PR специалистов, произошедших во время проведения деловой игры, приведет к повышению успеваемости не менее 30-40 процентов в экспериментальной группе по сравнению с контрольной группой при одинаковом времени занятий в экспериментальной и контрольной группах.

Мы использовали следующие 5 критериев оценки ожидаемых результатов лингводидактического тестирования диалогической речи: умение начать диалог с потенциальным клиентом; умение поддержать общение, обозначив интерес к теме исследования; умение запросить нужную информацию, уточняя полученные сведения и вежливо выясняя отношение респондентов к изучаемому вопросу; умение управлять диалогом, предлагая вернуться к обсуждаемой теме в случае нежелания респондента обсуждать именно эту тему; умение суммировать сказанное и подвести итог диалога.

Выполнение всех пяти критериев в полной мере обуславливало 100\% выполнения задания, при этом каждый отдельный критерий оценивался в 20\% при условии отличного выполнения.

Для лингводидактического тестирования монологической речи были выбраны следующие показатели: умение убедить слушателей в том, что тема актуальна; умение представить суть проблемы; умение представить собственную точку зрения и привести аргументы; умение дать оценку результатам выполненного проекта.
Выполнение всех четырёх критериев в полной мере обуславливало 100\% выполнения задания, при этом каждый отдельный критерий оценивался в 25\% при условии отличного выполнения.

Помимо этого, оценивались отдельно критерии грамматической и лексической грамотности, как при диалогическом, так и при монологическом высказывании. За каждую ошибку снимался один балл.

Исследование проводилось на базе МГлУ на факультете ИМО и СПН. В исследовании принимали участие обучающиеся 4 курса бакалавриата по специальности «Реклама и связи с общественностью»: 10 человек в контрольной группе и 11 человек в экспериментальной группе. Длительность эксперимента составила 1 семестр (с сентября по декабрь 2020).

Контрольная группа обучалась по рабочей программе для 4 курса бакалавриата направления «Реклама и связи с общественностью». Студенты контрольной группы также, как и студенты экспериментальной группы, проводили исследование потребительских рынков для железнодорожного транспорта в России и Великобритании, изучая материалы доступные в сети Интернет. После чего они должны были составить диалог на тему «Опрос общественного мнения по теме «Что хотят пассажиры железных дорог в России» между PR менеджером и пассажирами, используя в диалоге собранную информацию. Каждый студент, исполняющий роль PR менеджера, должен был опросить всех студентов, исполняющих роль пассажиров. После чего все PR менеджеры представляли свой доклад о том, каким образом они могут использовать полученную информацию для продвижения компании на международном рынке. Эти студенты не изучали методику Клотера Рапайя [7], и их внимание специально не фокусировали на выявлении культурно-окрашенных отличий и сходства между мнениями российских и английских пассажиров.

Эксперимент был представлен следующими этапами:

1. Одна часть экспериментальной группы исследовала потребительские рынки для железнодорожного транспорта в России, а другая - в Великобритании, используя информацию доступную в сети Интернет. С самого начала их попросили обратить особое внимание на культурно-окрашенные особенности мнений пассажиров.

2. Студенты изучали методику исследования национального культурного кода и готовились к проведению сессии по опросу пассажиров с использованием этой методики. Проведение опроса, которое проходило в форме множественных диалогов, оценивалось по пяти показателям.

3. Студенты выступали с докладом по результатам опроса, предлагая тот национальный культурный 
код, который они выявили, и его использование в компании по продвижению услуг железнодорожных компаний. Монологическое выступление студентов оценивалось по четырем показателям.

На контрольном этапе эксперимента мы учитывали число допущенных грамматических и лексических ошибок в написании предварительного эссе «Мои предложения по реновации железных дорог в России». Мы измеряли количество ошибок в экспериментальной и контрольной группах. У 11 студентов экспериментальной группы среднее количество ошибок равнялось 5,2. У 10 студентов контрольной группы среднее количество ошибок составило 5,3. Эмпирическое значение Крамера-Уэлча оказалось меньше критического значения, которое было равно 1,96 при заданной доверительной вероятности 0,95. Поэтому с вероятностью 0,95 различием показателей контрольной и экспериментальной групп можно пренебречь и считать интересующие нас педагогические количественные показатели совпадающими [3].

В конце эксперимента среднее количество ошибок В презентации монологического выступления студентов, представленной в письменном виде, составило 4,6 и 5,2 у студентов экспериментальной и контрольной групп соответственно. Эмпирическое значение Крамера-Уэлча оказалось выше критического значения, поэтому результат применения разработанной методики может с вероятностью 0,95 считаться позитивно ценным [3].

Экспериментальная группа представила следующие результаты. В процессе поиска информации, были выявлены основные ключевые моменты, по которым пассажиры в России и в Великобритании высказывали желание изменить или добавить услуги, которые оказывают железнодорожные компании. Среди выбранных студентами возможностей, о которых мечтают пассажиры России и/или Великобритании, были следующие: возможность резервировать место на поезде и/ или менять свой заказ перед и во время поездки (пассажиры России); возможность подтверждать действительность билета электронным способом без проверки его контролером (пассажиры Великобритании); возможность посмотреть схему уже купленных билетов и билетов в наличии в мобильном приложении (пассажиры России и Великобритании); возможность использовать мобильное приложение, чтобы найти свою платформу и место в поезде (пассажиры России и Великобритании); возможность выбрать любую дополнительную услугу заранее при бронировании места на поезде (пассажиры Великобритании); возможность заказать или отказаться от питания в поезде (пассажиры России); возможность получать бонусы по системе лояльности (пассажиры Великобритании); возможность автоматического возврата денег при отмене или задержке поезда (пассажиры Рос- сии); возможность поиска альтернативных маршрутов в мобильном приложении (пассажиры России и Великобритании) и др. Таким образом, студенты убедились, что желания пассажиров России и Великобритании подвержены влиянию культурных особенностей этих стран.

В процессе проведения сессий по выявлению культурного кода железных дорого России, студенты пришли к выводу о том, что в культурной традиции русского человека железные дороги всегда ассоциировались с переменами и романтикой. Также часто встречалось сравнение поездов дальнего следования, особенно в плацкарте, с коммуналкой: общий стол, знакомства, откровенные беседы до утра с малознакомыми людьми, алкоголь, драки, храп на весь вагон.

Пассажиры из Великобритании в общем довольны русскими поездами. Они отмечают, что для русских поезд дальнего следования - это второй дом, что зачастую отсутствие сервиса компенсируется хлебосольством и гостеприимством соседей по купе или плацкарте, которые всегда накормят яйцами, бутербродами с колбасой и вареной курицей.

Проанализировав результаты сессии, студенты пришли к выводу о том, что для русского пассажира путешествие по железной дороге ассоциируется с жизнью в коммунальной квартире, а для английских пассажиров путешествие по России по железной дороге связано прежде всего с ярко выраженным гостеприимством попутчиков. Таким образом, национальные культурные коды для российских железных дорог оказались связаны с понятиями дома и гостеприимства. Исходя из культурного кода «Гостеприимный дом», студенты разработали компании по продвижению путешествия по российской железной дороге на международный рынок.

Экспериментальная группа продемонстрировала в целом более высокие лингводидактические показатели диалогической речи (в среднем на 30 \%) и более высокие показатели монологической речи (в среднем на 40\%). Динамика развития диалогических и монологических речевых умений и навыков студентов подтвердила первоначальную гипотезу о повышении эффективности обучения английскому языку при формировании на занятиях элементов культурно-профессиональной компетенции с опорой на методику выявления национального культурного кода.

\section{Выво}

В данной статье мы рассмотрели квалификации, умения и навыки PR специалистов в сфере железнодорожного транспорта, которые востребованы на современном международном рынке, и выявили, что наиболее важным считается умение исследовать скрытые 
желания и потребности клиента, о которых даже сам клиент может и не знать и которые исследователи называют национальным культурным кодом. Для успешного продвижения на рынке, PR менеджер должен овладеть профессионально-культурной квалификацией исследования культурных кодов товаров и услуг потенциальных клиентов. Мы решили использовать процесс формирования элементов профессионально-культурной компетенции как инструмент для повышения эффективности обучения иностранному языку специальности будущих PR менеджеров. В процессе педагогического эксперимента студенты провели исследование материала, доступного в сети Интернет, и собрали информацию о мнении российских и английских пассажиров о путешествии по железной дороге в России. После чего студенты провели сессии, имитирующие профессиональную деятельность PR специалистов железной дороги, выявили национальный культурный код железной дороги, чтобы использовать его в дальнейшем в кампании по продвижению на рынке. Мы оценивали диалогическую и монологическую речь студентов экспериментальной группы. В результате проведения педагогического лингводидактического эксперимента, мы подтвердили выдвинутую нами гипотезу о том, что формирование элементов профессионально-культурной компетенции в процессе обучения иностранному языку специальности будущих PR менеджеров железной дороги будет способствовать как более эффективному и успешному освоению иностранного языке специальности, так и повышению интереса студентов к своей будущей профессии.

ЛИТЕРАТУРА

1. Ляхова Е.Г., Петрашевская Е.Г., Коршунова С. И., Волкова А.Ю., Глаголев А.Б. Роль российского культурного кода гостеприимства в обучении иностранным языкам студентов специальностей «Туризм» и «Управление гостиницами»/ Е.Г. Ляхова, Е.Г. Петрашевская, С. И. Коршунова, А.Ю. Волкова, А.Б. Глаголев // Международный научно-исследовательский журнал. - 2021. - № 1 (103) Часть 4. - 2021 - С. 140-145. - URL: http://research-journal.org/ pedagogy/rol-rossijskogo-kulturnogo-koda-gostepriimstva-v-obuchenii-innostrannym-yazykam-studentov-specialnostej-turizm-i-upravlenie-gostinicami/ (дата обращения: 20.07.2021.). doi: 10.23670/IRJ. 2021.103.1.115.

2. Перфилова Г.В. Примерная программа по дисциплине «Иностранный язык» для подготовки бакалавров (неязыковые вузы) / Г.В. Перфилова. - Москва: ИПК МГЛУ «Рема», 2011. -30 c.

3. Cohen J. Statistical power analysis for the behavioral sciences (2nd ed.)/ J. Cohen. - Routledge, 1988. - pp. 67-590.

4. Friman M., Gärling T., Ettema D., Olsson L.E. How does travel affect emotional well-being and life satisfaction?/ M. Friman, T. Gärling, D. Ettema, L.E. Olsson // Transp. Res. Part A Policy Pract., 106 (2017), 170-180, 10.1016/j.tra.2017.09.024Article Download PDF View Record in ScopusGoogle Scholar

5. Liakhova E., Moroz N. Russian culture code research educational game as a tool to enhance professional English language training of future PR specialists / E. Liakhova, N. Moroz // INTED2020 Proceedings. - pp. 140-149, 2020. WOS:000558088800024. D0I: 10.21125/inted.2020.0084

6. Oliveira L.C., Fox C., Birrell S., Cain R. Analysing passengers' behaviours when boarding trains to improve rail infrastructure and technology/ L.C. Oliveira, C. Fox, S. Birrell, R. Cain // Robot. Comput. Integr. Manuf., 57 (2019), 282-291, 10.1016/j.rcim.2018.12.008Article Download PDF CrossRef View Record in ScopusGoogle Scholar

7. Rapaille C. The culture code: An ingenious way to understand why people around the world live and buy as they do/ C. Rapaille. - N.Y.: Broadway Books, 2006. $407 \mathrm{p}$.

8. Tambovtsev V. The myth of the "Culture code" in economic research [Электронный ресурс] / V. Tambovtsev // Russian Journal of Economics. - № 1. pp. 294-315. - URL: https://doi.org/10.1016/j.ruje.2015.12.006 (дата обращения: 23.06.2021).

9. Vaičiūte Kristina \& Skirmantienè Jolanta \& Domanska Lidia. Assessment of Transport Specialists' Competencies in Transport/Logistics Companies/K. Vaičiūtė, J. Skirmantiené, L. Domanska // Procedia Engineering. 187. 628-634, 2017, 10.1016/j.proeng.2017.04.423.

(с) Ляхова Елена Георгиевна (liakhoval@mail.ru), Федоткина Елена Викторовна (fedotkina@mail.ru). 